Cahiers $d u$ MONDE RUSSE

\section{Cahiers du monde russe}

Russie - Empire russe - Union soviétique et États indépendants

$49 / 4 \mid 2008$

Destins individuels et terreur. Jeunesse dans la société post-stalinienne

\title{
Cécile Vaissié, Les ingénieurs des âmes en chef
}

\section{Sophie Cœuré}

\section{(2) OpenEdition}

12 Journals

\section{Édition électronique}

URL : https://journals.openedition.org/monderusse/6962

DOI : 10.4000/monderusse.6962

ISSN : $1777-5388$

Éditeur

Éditions de l'EHESS

\section{Édition imprimée}

Date de publication : 28 décembre 2008

Pagination : 774-776

ISBN : 978-2-7132-2197-2

ISSN : $1252-6576$

\section{Référence électronique}

Sophie Cœuré, "Cécile Vaissié, Les ingénieurs des âmes en chef », Cahiers du monde russe [En ligne], 49/4 | 2008, mis en ligne le 24 décembre 2009, consulté le 07 septembre 2022. URL : http://

journals.openedition.org/monderusse/6962 ; DOI : https://doi.org/10.4000/monderusse.6962

Ce document a été généré automatiquement le 2 septembre 2022.

Tous droits réservés 


\title{
Cécile Vaissié, Les ingénieurs des âmes en chef
}

\author{
Sophie Cœuré
}

\section{RÉFÉRENCE}

Cécile VAISSIÉ, Les ingénieurs des âmes en chef. Littérature et politique en URSS

(1944-1986). Paris : Belin, 2008, 515 p.

1 Reprenant en titre la célèbre formule de Stalin enjoignant en 1932 aux écrivains soviétiques de devenir les "ingénieurs de l'âme humaine », Cécile Vaissié propose de relire et d'approfondir à la lumière de nouvelles archives le débat sur la relation de subordination entre littérature et politique en URSS. Pour mener son impressionnant travail documentaire, sans équivalent jusqu'à présent, l'auteur a utilisé les archives du parti communiste, des Unions des écrivains et les fonds personnels dans les archives littéraires, de préférence aux biographies contemporaines et aux souvenirs, qu'elle utilise cependant par croisement ou par opposition. Dès lors, l'ouvrage cherche à saisir l'implication des élites littéraires dans le processus d'étouffement de la liberté d'opinion et d'instrumentalisation de la création, à travers le tableau des instances intervenant dans le champ littéraire et la prosopographie croisée de quatorze personnalités. Aux cinq dirigeants successifs de l'Union fédérale des écrivains soviétiques de 1944 à 1986 (Nikolaj Tihonov, Aleksandr Fadeev, Aleksej Surkov, Konstantin Fedin, Georgij Markov), et à leurs homologues de l'Union des écrivains de Russie (Leonid Sobolev et Sergej Mihalkov) et de l'organisation locale de Moscou (Konstantin Fedin, Sergej Mihalkov, Georgij Markov déjà cités, ainsi que Stepan Ščipačev, Sergej Narovčatov, Sergej Smirnov et Feliks Kuznetsov), l'auteur ajoute trois «stars littéraires»: Konstantin Simonov, Aleksandr Tvardovskij et Mihail Šolohov.

2 Au fil de six grandes parties qui remettent en question les chronologies convenues et tissent habilement les destins, Cécile Vaissié retrace la mise en place et la pérennisation des instances de direction de la production littéraire : le parti (avec un utile historique 
de l'organigramme des directions chargés de l'agitation et de la propagande, l'Agitprop, pages 496-498) et l'Union des écrivains, fondée en 1934. Ces instances partagent avec l'ensemble des organismes de l'État soviétique les processus de gonflement numérique et de vieillissement, mais aussi, comme le montre très bien l'auteur, l'opacité des statuts, entre permanents rémunérés (dont certains nommés directement par le parti ou par le KGB, ou provenant d'organes extérieurs, ministères ou Komsomols) et bénévoles présents au titre des "activités sociales». C'est après 1956 qu'est créé un poste de "secrétaire chargé des questions d'organisation ", signe du poids croissant du KGB dans l'institution, tandis que naît en 1958 l'Union des écrivains " de Russie », nationaliste et conservatrice, contrepoids à l'Union des écrivains de Moscou. L'étude précise de cas célèbres (l'affaire Pasternak, les procès de Brodskij ou de Sinjavskij, l'exclusion de Solženicyn) ou moins connus, comme le destin brisé de Tvardovskij à la tête de la revue Novyj Mir, permet à l'auteur de démonter avec précision les mécanismes politiques et bureaucratiques du contrôle, de la censure, ou au contraire de l'incitation. Malgré une « apparente rondeur » des relations dans la période post-stalinienne, où le comité central consulte avant d'imposer, le contrôle pyramidal des organisations littéraires par leurs comités de parti ne se relâche pas. L'Agitprop décide de tout: publications, tirages, sommaires des revues, conférences, visites d'écrivains étrangers, etc. Elle place les écrivains au service des grandes campagnes politiques, que ce soit la dénonciation du « cosmopolitisme » - c'est-à-dire des auteurs juifs - ou l'éloge de l'agriculture. Elle leur impose le cas échéant de reécrire leurs ouvrages en fonction de normes changeantes. L'omniprésence de Stalin, puis de Hruščev et Brežnev est également frappante, même si les sources directes manquent encore.

Dès lors, l'analyse institutionnelle semble conforter l'usage fréquent par l'auteur du terme "État-parti », et l'affirmation par son préfacier, Claude Lefort, de la "persistance du totalitarisme jusqu'au milieu des années 1980 ». Pour autant, l'étude approfondie d'itinéraires biographiques vient nuancer cette vision «totalitariste». Cécile Vaissié éclaire à maintes reprises les stratégies complexes d'accommodement des écrivains, leur légitimation par l'appartenance au parti ou la justification de leur bonne conduite pendant la guerre civile puis la « Grande Guerre patriotique ». Elle analyse finement les jeux personnels et institutionnels, entre les Unions des écrivains et les revues, entre auteurs et critiques. Elle propose enfin un tableau, éclaté au fil des portraits, mais qui reste saisissant, de la vie quotidienne, du mécanisme des rétributions matérielles (le cumul des salaires, les droits d'auteurs selon les tirages et non les ventes, les prix), de la distribution des appartements, des séjours de vacances, de l'accès aux soins, des voyages à l'étranger. Le personnage de Simonov illustre une distinction croissante dans l'apparence et dans la vie sociale, entre quelques privilégiés et les milliers d'écrivains membres des unions fédérale ou locales.

4 Sans prendre position plus avant dans les discussions méthodologiques sur la place $d u$ privé et du public en URSS ou sur l'analyse sociologique des interactions entre " champ intellectuel " et "champ politique», Cécile Vaissié choisit d'offrir une plongée saisissante dans des psychologies tourmentées et des corps meurtris (alcoolisme et suicide de Fadeev, eczéma de Simonov). Le rite de soumission, de confession et d'expiation (prorabotka), perpétué au fil des réunions et des plénums, la mise en accusation des collègues et amis qui n'empêche nullement les dîners en commun, les vengeances privées, entraînent une cascade d'autojustifications, de dénis, et de tensions douloureuses entre la réalité vécue et une conception « morale » de la littérature héritée du $x_{X} X^{e}$ siècle. Faute de sources, la question du lien entre cette politisation et la réception 
par les lecteurs soviétiques d'ouvrages officiels que l'historien du xxI siècle peine à lire, reste ouverte. Laissant parfois percer une dénonciation passionnée de la "médiocrité " triomphante, de "l'asservissement » et de "l'entreprise de crétinisation générale », l'auteur conclut de manière fort convaincante sur les lourdes conséquences pour la Russie contemporaine de cette co-gestion intéressée de l'État par les élites intellectuelles russes. 